\title{
The importance of emotional intelligence and meaning in life in psycho-oncology
}

\author{
Andreia Pereira Teques'*, Glória Bueno Carrera', José Pais Ribeiro², Pedro Teques³ and Ginés Llorca Ramón' \\ 'Faculty of Medicine, University of Salamanca, Department of Psychiatry and Medical Psychology, Salamanca, 4445-577, Spain \\ ${ }^{2}$ Faculty of Psychology and Educational Sciences, University of Porto, Department of Psychology, Porto, Portugal \\ ${ }^{3}$ Sport Sciences School of Rio Maior, Polytechnic Institute of Santarem, Department of Sport Psychology, Santarém, Portugal
}

*Correspondence to:

Psychiatry and Medical

Psychology, Faculty of Medicine,

University of Salamanca,

Salamanca, 4445-577 Spain.

E-mail: apsousapereira@gmail. com

Received: 17 November 2014

Revised: 21 April 2015

Accepted: 6 July 2015

\begin{abstract}
Objective: Cancer was considered the disease of the 20th century, and the management, treatment, and adaptation of patients to general wellbeing were worldwide concerns. Emotional intelligence has frequently been associated with wellbeing and considered one important factor to optimal human functioning. The purpose of the present study was to test the differences regarding the relationship between emotional intelligence, purpose in life, and satisfaction with life between cancer and healthy people.
\end{abstract}

Methods: This model was tested using structural path analysis in two independent samples. First, in a general Portuguese population without chronic disease, 214 participants $\left(n_{\text {male }}=41, n_{\text {female }}=173\right.$; $\left.M_{\text {age }}=53\right)$. Second, in 202 patients with cancer $\left(n_{\text {male }}=40, n_{\text {female }}=162 ; M_{\text {age }}=58.65\right)$. A two-step methodology was used to test the research hypothesis.

Results: First, a confirmatory factor analysis supported the measurement model. All factors also show reliability, convergent, and discriminate validity. Second, the path coefficients for each model indicate that the proposed relationships differ significantly according to the groups. The perception capacities of emotional intelligence were more related to satisfaction with life and purpose in life in oncologic patients than in the general population without chronic disease, specifically emotional understanding and regulation. Likewise, the relationship between purpose in life and satisfaction with life in oncologic patients was significantly higher than for the general population.

Conclusion: The current findings thus suggest that emotional intelligence and purpose in life are potential components to promoting satisfaction in life in healthy people and more so in oncologic patients.

Copyright @ 2015 John Wiley \& Sons, Ltd.

\section{Background}

Cancer has become a worldwide priority by being identified as a major cause of death [1]. The increased survival rate of cancer patients poses a major challenge, in particular, because more survivors demand a greater need for intervention and understanding of the phenomenon, with the goal of maintaining and restoring the quality of life of survivors in their multiple facets [2].

The need to provide a better life for cancer patients is in accordance with positive psychology, which focuses on understanding human wellbeing, and studying multiple psychological variables that promote or relate to wellbeing causes, such as meaning in life and satisfaction with life, [3]. Similarly, psycho-oncology studies the variables and/or positive factors in promoting or protecting wellbeing under oncologic diseases adversity [4]. This significant interest in the study of positive variables has emerged more recently in the health-disease process, particularly in the study of emotional intelligence [5].

This study aims to understand how some positive variables are related, such as meaning/purpose in life (PIL), satisfaction with life (SWL), and emotional intelligence (EI), both in the presence and absence of cancer. Thus, on one hand, we suggest that people without chronic disease that perceive themselves as being emotionally intelligent have PIL that increases life satisfaction. On the other hand, we suggest that cancer patients who perceive more EI capacities have PIL, thereby feeling more SWL. This hypothetical model is represented in Figure 1. According to the literature, we also expect that healthy people percept more EI capacities, feel more SWL, and live a life with more meaning compared with cancer patients.

Emotional intelligence and satisfaction with life in health and disease

Emotional intelligence presents itself as a variable that promotes health, influencing both physical and mental health (e.g., [6]). In the understudied relationship between EI and wellbeing in cancer disease, EI increases the perception of SWL and a reduced vulnerability in the 


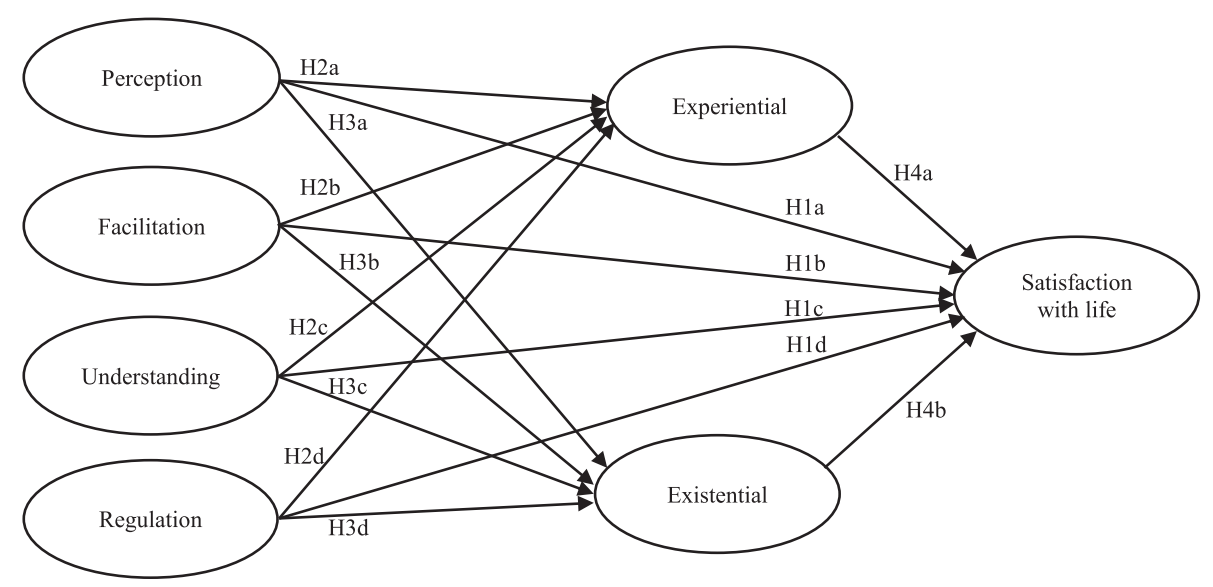

Figure I. Hypothesized model

disease process (e.g., [7]). Studies made in populations without chronic disease reveal that EI has been significantly associated with SWL (e.g., [8]).

Accordingly, we hypothesized (Hypothesis 1) that EI components (a-d) are positively related with SWL.

\section{Emotional intelligence and purpose in life in health and} disease

The scarce research on the relationship between EI and PIL refers that this relationship is mediated by the quality of social relations in general population subjects [9] and that EI significantly influences successful performance, happiness, and wellbeing, decisive factors to find PIL [10].

Thus, we hypothesized (Hypothesis 2) that EI components $(\mathrm{a}-\mathrm{d})$ would be related to existential meaning and with experiential meaning (Hypothesis 3).

\section{Purpose in life and satisfaction with life in health and disease}

Purpose in life is an important factor in healthy human functioning and health promotion [11]. There are many studies with healthy samples that highlight the significant relationship between SWL and PIL (e.g., $[12,13]$ ).

In oncologic disease, PIL promotes more efficient adaptation and quality of life, even in patients with more severe diagnoses [14].

Therefore, we hypothesized (Hypothesis 4) that PIL dimensions $(\mathrm{a}-\mathrm{b})$ will be associated with SWL.

\section{Methods}

\section{Participants}

A sample of 416 participants, 214 (male $=41$ and female $=173)$ from the Portuguese general population and $202($ male $=40$ and female $=162)$ with oncologic disease, volunteered for the study. Participants ranged in age from 24 to 87 years. The two subsamples were proximal in age with a mean age of 58.65 [standard deviation $(S D)=11.97]$ years for the subsample with oncologic disease, and a mean age of $53(S D=19.21)$ years for the subsample from the general population. Among the participants with oncologic disease, $49.5 \%$ were breast cancer patients, $17.8 \%$ intestine, and $7.9 \%$ stomach. None of them had cognitive impairments that would limit their understanding of the measures administered.

\section{Measures}

\section{Emotional intelligence}

The Emotional Intelligence Self-Perception Questionnaire ([15]) was designed to measure individuals' self-perceived EI abilities and skills. The Emotional Intelligence SelfPerception Questionnaire consists of 18 items subdivided into four dimensions: emotional perception, evaluation and expression; use emotions to facilitate thought; emotional understanding and analysis; and emotional regulation. Participants responded on a 5-point scale ranging from strongly disagree (1) to strongly agree (5).

\section{Purpose in life}

We assessed purpose in life by administering the Portuguese revised version of the Purpose in Life Test (PIL-R; [16]). The PIL-R contains 20 items with a 7-point type response format. The PIL-R used in the current study comprised two factors, one involving satisfaction with existential meaning and the other dealing with experiential meaning. Higher scores are consistent with reports of greater personal meaning. The psychometric properties of the two-factor version of this scale have been supported by previous research (e.g., [17]).

\section{Satisfaction with life}

The 5-item Portuguese version of the Satisfaction with Life Scale (SWLS; [18]) was employed to assess 
participants' self-perceived global life satisfaction. Participants responded on a 7-point scale ranging from $1=$ strongly disagree to $7=$ strongly agree . The internal reliability of this measure has been supported by previous research (e.g., [19]).

\section{Procedure}

The hospital's ethics committee provided the necessary permission and ethical approvals. The participants provided informed consent to volunteer for the study. A multi-section questionnaire was distributed to the participants with oncologic disease in two Portuguese hospitals and for the general population subsample, in community gathering centers. The subjects without chronic disease were selected in order to approximate to sociodemographic characteristics of the oncologic population. The cancer patients were invited to participate in waiting time for consultations or treatments. In both groups, the attitude of the participants was fully participatory.

\section{Data analysis}

Data were analyzed using AMOS 20, and a two-step maximum likelihood structural equation model was performed. First, a confirmatory factor analysis was conducted to assess the measurement model for each of the subsamples. Internal consistencies of the constructs were examined using congeneric, tau-equivalent, and parallel models [20]. The congeneric model $(\mathrm{H})$ is the least restrictive and assumes that each individual item measures the same latent variable, with possible different scales, degrees of precision, and magnitude of error. The tau-equivalent model $(\mathrm{H} \lambda)$ implies that individual items measure identical constructs. Tau-equivalent tests measure the same constructs to the same degree but are not equally reliable. The parallel model $(\mathrm{H} \lambda \theta)$ is the most restrictive measurement model. Parallel test load on the same construct to the same degree and have equal error. The reliability value was estimated by squaring the implied correlation between the latent true variable and the observed variable [21]. Convergent validity was evaluated through the average variance extracted (AVE), while discriminant validity was established when AVE for each construct exceeded the squared correlations between that construct and any other [22].

Second, structural equation model was used for each group to test research hypotheses. Goodness of fit for both the measurement and structural models was assessed with the ratio of chi-squared $\left(\chi^{2}\right)$ to its degrees of freedom, Tucker-Lewis Index (TLI), comparative-of-fit index (CFI), standardized root mean square residual (SRMR), and root mean square error of approximation (RMSEA) [23]. In addition, a multi-group analysis was performed to verify if the path coefficients for the hypotheses differ among the models for the oncologic disease and general population groups. The model's invariance was tested by comparing the unconstrained model with the model constraining the structural weights [24]. The significance of the structural weights was evaluated using the Z-tests produced by AMOS, and statistical significance was assumed at a 0.05 level.

\section{Results}

\section{Preliminary analysis}

An inspection of the data revealed that missing values covered $3.6 \%$ of cells in the raw data matrix, with no pattern of missing data. Therefore, missing data were imputed using AMOS's regression procedure. Nine cases emerged either as univariate $(z>3.00)$ or multivariate outliers in the general population subsample (squared Mahalanobis distance $=p 1<0.001, p 2<0.001)$. These participants were removed prior to conducting any further analysis. The skewness values for the items used in this study ranged from -0.12 to 2.89 , while kurtosis values ranged from -1.78 to 4.51 . These values do not represent univariate non-normality [25]. However, Mardia's coefficient $(88.16, p=0.00)$ exceeded the expected values for the assumption of multivariate normality [24]. To cope with this, we applied a Bollen-Stine bootstrap (B-S) on 2000 samples to the subsequent analysis [26]. Also, collinearity was tested with all study variables, resulting in variance inflation factors ranging from 1.06 (perception of emotions) to 1.41 (SWL), within the limits accepted for regression analysis [23] (Table 1).

\section{Measurement model}

The results of the confirmatory factor analysis in the model for both subsamples showed that the factor loadings of five items from existential and three items from experiential meaning failed to exceed the cutoff point of 0.50 [23] and were consequently eliminated in both models (Table 1). Re-specifications of these two constructs are consistent with structural factor confusion in evaluation of PIL [17,11]. After these procedures, all items showed high to moderate factor loadings, ranging from 0.52 to 0.87 (oncologic disease patients) and from 0.53 to 0.87 (general population), providing evidence that each item appropriately captured its respective factor. As shown in Table 1, the reliability indices fitted best with the congeneric model in all of the latent constructs with values above the recommended 0.70 threshold in both models, except for existential meaning ( 0.62 for the oncologic patients and 0.64 for the general population). Traditionally, existential meaning has indicated low reliability (e.g., [16]), but because of its theoretical importance, it was retained in the model for further analysis. All AVE values were close to or greater than the 0.50 standard for 
Table I. Factor loadings, reliabilities, and AVE

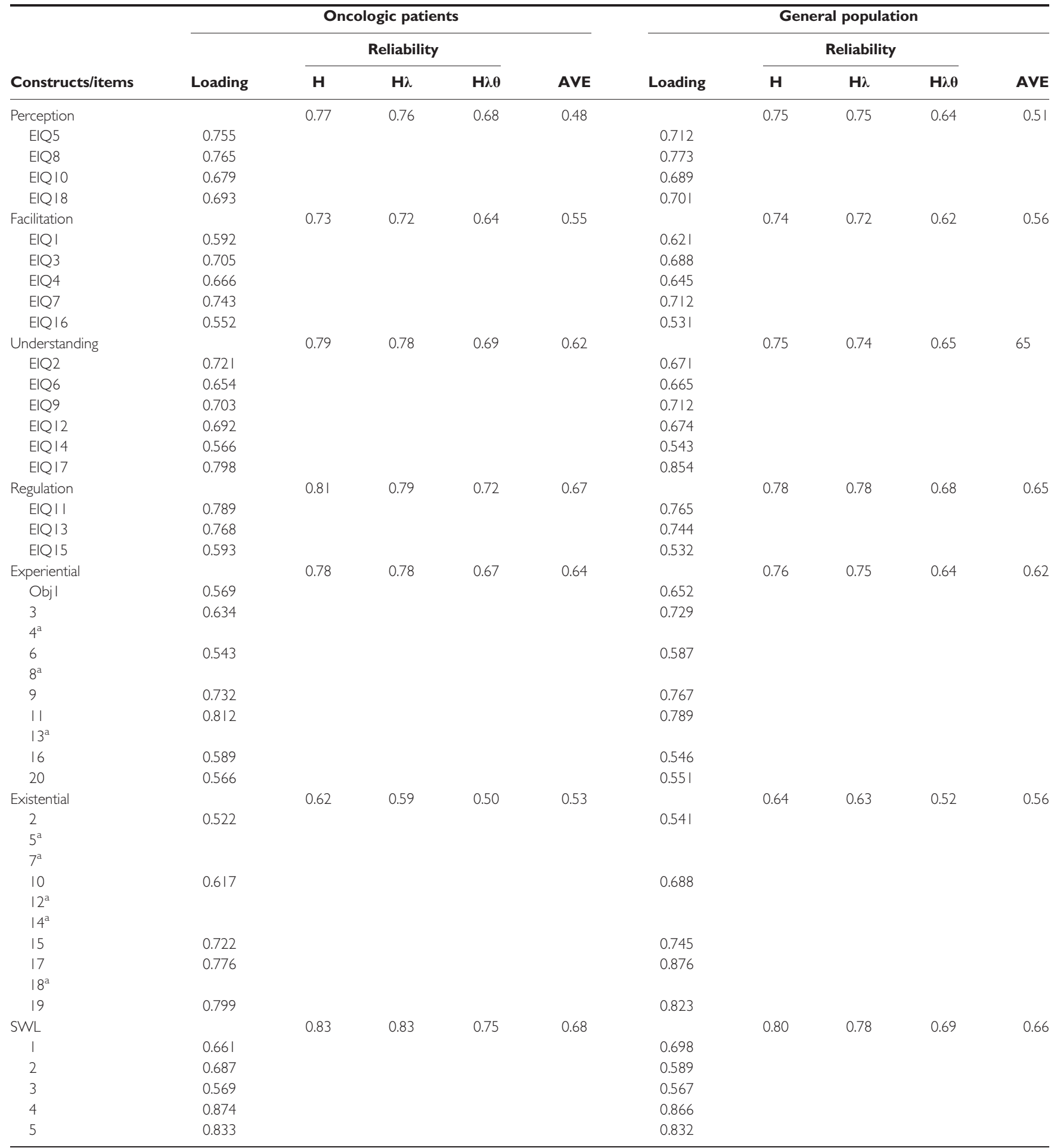

AVE, average variance extracted; $H$, congeneric model; $H \lambda$, tau-equivalent model; $H \lambda \theta$, parallel model; SWL, satisfaction with life. altem eliminated because of the lack of individual reliability.

convergent validity [22], ranging from 0.48 to 0.68 (oncologic patients), and from 0.51 to 0.66 (general population).

Descriptive statistics of the measures used in both models and its correlations are reported in Table 2. The mean scores for the constructs related to the two subsamples showed that general population respondents have higher SWL $(M=4.91, S D=1.02)$. However, oncologic patients revealed higher regulation of emotions 
Table 2. Means $(M)$, standard deviations $(S D)$, and correlation matrix

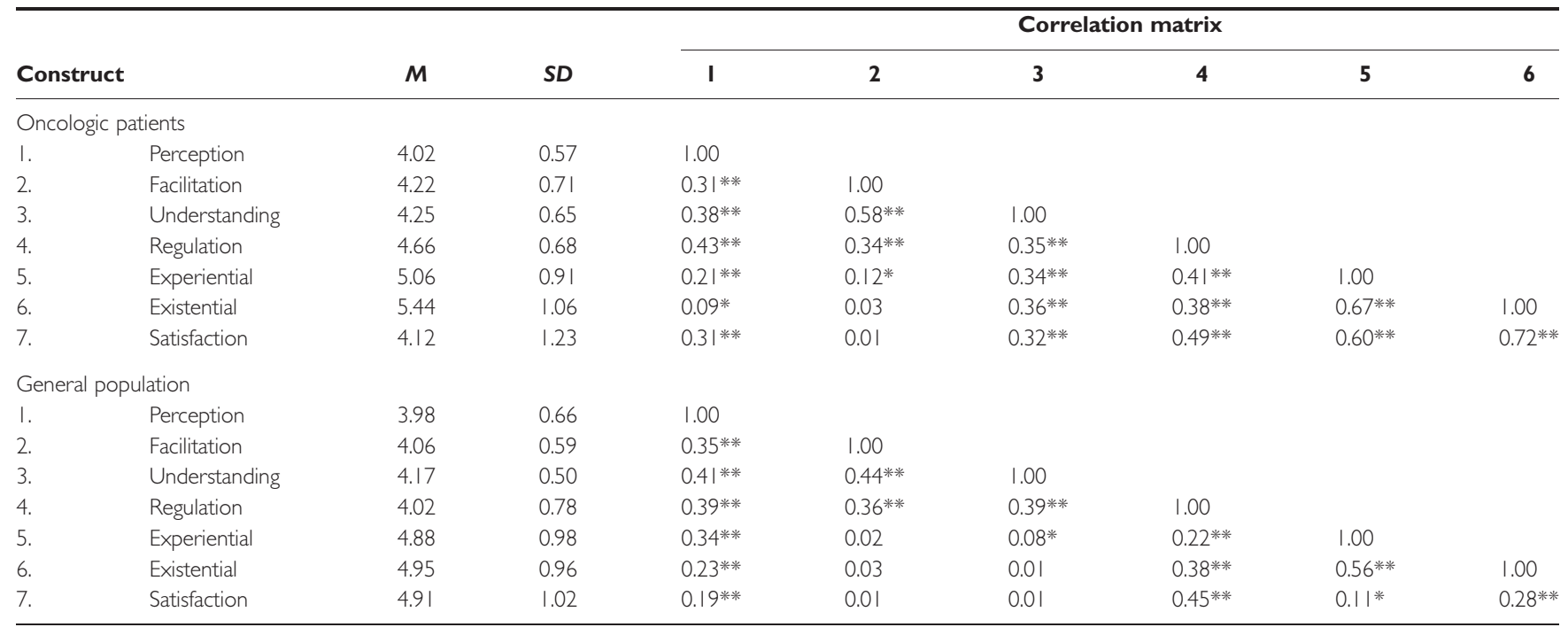

No correlations failed the average variance extracted test of discriminant validity. $* p<0.05$;

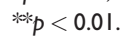

$(M=4.95, S D=0.77)$ and existential meaning $(M=5.44$, $S D=1.06$ ). Discriminant validity of the measures was accepted, given the squared correlations between each construct, and all other constructs were lower than the AVE values for each independent construct in the two models. Furthermore, the results of the final measurement model using oncologic patients $\left[\chi^{2}(443)=661.15\right.$, B-S $p<0.001$, CFI $=0.94, \quad \mathrm{TLI}=0.93$, RMSEA $=0.05$ $(\mathrm{CI}=0.041,0.052), \mathrm{SRMR}=0.05]$ and general population $\left[\chi^{2}(443)=589.46, \mathrm{~B}-\mathrm{S} p<0.001, \mathrm{CFI}=0.95, \mathrm{TLI}=0.95\right.$, RMSEA $=0.04 \quad(\mathrm{CI}=0.033,0.041), \quad \mathrm{SRMR}=0.05]$ responses, showed an acceptable fit to the data. The TLI and CFI values in both models were greater than the recommended threshold of 0.90 [23]. In addition, RMSEA and SRMR were within the acceptable criteria [24]. Overall, the measurement model for each group of respondents showed an acceptable fit to the data, and consequently, the structural model was examined.

\section{Structural model}

The examination of the structural model included a test of the overall model fit, as well as individual tests of the relationship between the latent constructs. The overall assessment of the structural models was found to be acceptable for both oncologic patients $\left[\chi^{2}(540)=546.16\right.$, B-S $p<0.001$, CFI $=0.96$, TLI $=0.95$, RMSEA $=0.05$ $(\mathrm{CI}=0.041,0.052), \mathrm{SRMR}=0.04]$ and general population $\left[\chi^{2}(540)=689.46, \mathrm{~B}-\mathrm{S} p<0.001, \mathrm{CFI}=0.94, \mathrm{TLI}=0.93\right.$, $\mathrm{RMSEA}=0.05(\mathrm{CI}=0.043,0.056), \mathrm{SRMR}=0.05]$ models . The path coefficients for each model are illustrated in Table 3, indicating that the proposed relationships differ significantly between the groups. Emotional perception showed a significant effect on SWL in both models $(p<0.01)$. The effect of emotional facilitation on SWL was not significant in both models $(p>0.05)$. In turn, the effect of emotional understanding on SWL was significant for oncologic patients $(\beta=0.32, p<0.01)$, while not significant for the general population $(p>0.05)$. The relationship between emotional regulation and SWL was significant for both groups (oncologic patients: $\beta=0.47, p<0.01$; general population: $\beta=0.33, p<0.01$ ). Moreover, emotional perception, understanding, and regulation showed significant effects on experiential meaning for both groups $(p<0.05)$, whereas the relationship between emotional facilitation and experiential meaning were not significant for both groups $(p>0.05)$. Emotional perception and regulation showed significant effects on existential meaning $(p<0.05)$. In contrast, emotional facilitation was not significant in predicting existential meaning for both groups $(p>0.05)$. In addition, emotional understanding presented significant effects on existential meaning in oncologic patients $(\beta=0.39$, $p<0.01)$ but not in the general population $(p>0.05)$. The path coefficients between existential meaning and SWL were significant for both oncologic patients $(\beta=0.75$, $p<0.01)$ and the general population $(\beta=0.18, p<0.01)$. In contrast, experiential meaning was not significant in predicting SWL for the general population $(p>0.05)$ and showed a significant effect for the oncologic patients group $(\beta=0.59, p<0.01)$. Together, EI components and PIL variables accounted for approximately $24 \%$ of the variance in SWL for oncologic patients $\left(R^{2}=0.24\right)$ and $16 \%$ for the general population $\left(R^{2}=0.16\right)$.

In addition, the summary of the differences within the path coefficients in the models for both the oncologic patients and the general population is presented in Figure 2. 
Table 3. Summary results of the structural model for each of the subsamples

\begin{tabular}{|c|c|c|c|c|c|c|c|}
\hline & \multirow[b]{2}{*}{ Path } & \multirow[b]{2}{*}{ Confirmed? } & \multicolumn{2}{|c|}{ Oncologic patients } & \multicolumn{2}{|c|}{ General population } & \multirow{2}{*}{$\begin{array}{c}\text { Power } \\
(I-\beta)\end{array}$} \\
\hline & & & $\beta$ & Z-value & $\beta$ & Z-value & \\
\hline $\mathrm{HIa}$ & Perception $\rightarrow$ Satisfaction & Yes & $0.28 * * *$ & 9.15 & $0.34 * * *$ & 11.34 & 0.37 \\
\hline $\mathrm{HIC}$ & Understanding $\rightarrow$ Satisfaction & Partial & $0.32 * * *$ & 11.67 & 0.01 & 0.16 & 0.99 \\
\hline HId & Regulation $\rightarrow$ Satisfaction & Yes & $0.47 * * *$ & 22.55 & $0.33^{* * * *}$ & 11.15 & 0.90 \\
\hline $\mathrm{H} 2 \mathrm{a}$ & Perception $\rightarrow$ Experiential & Yes & $0.16 * *$ & 6.78 & $0.22 * *$ & 8.33 & 0.46 \\
\hline $\mathrm{H} 2 \mathrm{~d}$ & Regulation $\rightarrow$ Experiential & Yes & $0.41 * *$ & |8.7| & $0.32 * *$ & 11.88 & 0.60 \\
\hline $\mathrm{H} 3 \mathrm{a}$ & Perception $\rightarrow$ Existential & Yes & $0.22 *$ & 7.36 & $0.18 *$ & 7.16 & 0.27 \\
\hline $\mathrm{H} 3 \mathrm{~b}$ & Facilitation $\rightarrow$ Existential & No & 0.01 & 0.45 & 0.01 & 0.15 & 0.05 \\
\hline $\mathrm{H} 3 \mathrm{c}$ & Understanding $\rightarrow$ Existential & Partial & $0.39 * *$ & 17.54 & 0.01 & 0.17 & 0.99 \\
\hline H3d & Regulation $\rightarrow$ Existential & Yes & $0.45 * *$ & 21.34 & $\left.0.4\right|^{*} * *$ & 20.56 & 0.20 \\
\hline $\mathrm{H} 4 \mathrm{a}$ & Experiential $\rightarrow$ Satisfaction & Partial & $0.59 * *$ & 33.21 & 0.03 & 1.34 & 0.99 \\
\hline
\end{tabular}

${ }^{\text {a}}$ Based on Z-tests for differences between parameters. $* p<0.05$

$* * p<0.01$.

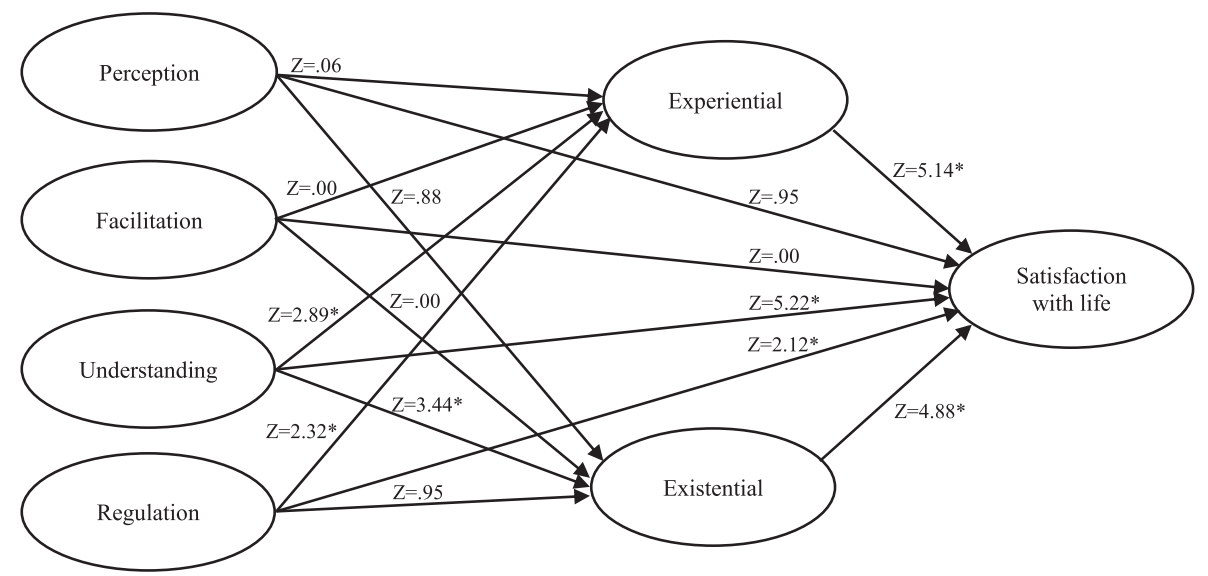

Figure 2. Z-tests for differences in structural parameters between both subsamples. $* p<0.05$

The fit of the unconstrained model $\left[\chi^{2}(1080)=846.09\right.$, B-S $p<0.001$, CFI $=0.93$, TLI $=0.91$, RMSEA $=0.03$ $(\mathrm{CI}=0.032,0.037), \mathrm{SRMR}=0.04]$ was acceptable, as well as for the model constraining the structural weights $\left[\chi^{2}(540)=936.61, \mathrm{~B}-\mathrm{S} p<0.001, \mathrm{CFI}=0.92, \mathrm{TLI}=0.90\right.$, RMSEA $=0.03(\mathrm{CI}=0.033,0.038), \mathrm{SRMR}=0.04]$. The $\chi^{2}$ statistic indicated that these models were significantly different from one another $\left[\Delta \chi^{2}(28)=90.52, p=0.000\right]$, while the $Z$-tests for differences between structural parameters revealed that seven proposed relationships differ significantly according to the oncologic patients and general population responses. Specifically, emotional understanding showed a significantly different effect on SWL $(Z=5.12, p<0.05)$, as well as on experiential $(Z=2.89$, $p<0.05)$ and existential meaning $(Z=3.44, p<0.05)$. Moreover, emotional regulation showed significantly different effect on SWL $(Z=2.12, p<0.05)$ and on experiential meaning $(Z=2.32, p<0.05)$. Additionally, the relationship between experiential $(Z=5.14, p<0.05)$ and existential meaning $(Z=4.88, p<0.05)$ on SWL was significantly different between oncologic patients and the general population.

A post hoc statistical power analysis was performed for differences between the oncologic patients and general population proportions $(p 1-p 2)$. To estimate statistical power $(1-\beta), Z$-test with optional arcsin transformation was used (GPower 3.1) [27]. The alpha level used for this analysis was $p<0.05$. The post hoc analyses revealed statistical power for differences between groups considered to be low (0.05) and high (0.99) using the recommended level of 0.80 or above (Table 3 ).

\section{Discussion}

The purpose of the present study was to examine the relationship between the components of EI and PIL, SWL, 
and its differences in people with and without oncologic disease.

Pertaining to the first hypothesis, in the general population, perception and emotion regulation were significantly related with SWL; facilitation and emotional understanding were not. In oncologic patients, perception, understanding, and emotional regulation had a significant relationship with SWL, and emotional facilitation did not. In this context, the results reinforce that subjects who perceive themselves to be emotionally intelligent feel SWL, similar to previous studies that showed a positive relationship between EI and SWL (e.g., [8]). More precisely, subjects who are aware of how they feel, resolve emotional situations in a superior way and experience greater wellbeing, as compared with subjects who display less clarity regarding their feelings [28]. When it comes to studies conducted with oncologic patients, which evaluate the specific relationship between EI and SWL, Guzmán and Alarcón found significant relationships between understanding and emotional regulation with SWL. In the same direction, EI shows the positive effects in the context of pain and chronic diseases such as cancer, because EI capacities are pre-eminent in confronting the stress associated with the disease, minimizing its impact and facilitating adaptation [29]. In this sense, we understand the curious results that cancer patients have a more significant relationship between EI and SWL than the general population. It is curious to the extent that the EI is associated with and promotes health states (e.g., $[5,6])$, as well as associated with a more wellbeing in healthy subjects compared with individuals with a chronic disease [30]. Whereas, therefore, EI as a moderator the relationship between stressful experiences and mental health [31] to Hypothesis 2, the results showed that in the general population, perception and emotion regulation correlated positively with experiential and existential dimensions of meaning. Emotional facilitation was unrelated to both dimensions. In addition, emotional understanding was significantly related with experiential dimension but not with existential meaning. The relationship between experiential and existential dimensions of meaning in oncologic patients is significant in perception, understanding, and emotional regulation, while emotional facilitation did not correlate positively with any dimension. The results of this study corroborate that emotion regulation is significantly related with PIL [9], likewise the dimension of emotional perception [32]. Meanwhile, the results of Zysberg's study [10] did not present positive associations between EI and PIL. Because of a lack of studies that examine these associations in oncologic patients, future research should ascertain the extent to which EI and PIL are related to chronic diseases.

For Hypothesis 3, we analyzed the relationship between PIL and SWL. The results showed that in the general population, the existential dimension of meaning has a positive relationship with SWL, while experiential dimension does not. Oncologic patients revealed a significant relationship between experiential and existential dimensions of meaning and SWL. The results demonstrate a positive relationship between PIL and SWL, corroborating the existing literature (e.g., [11]). In the oncologic context, PIL is associated with wellbeing in general, as well as with promotion of quality of life in patients [14,33]. Thus, oncologic patients who find PIL also reveal SWL [34]. Fegg et al. [35] found similar interesting results to those obtained in this investigation, that is, that the oncologic patient, compared with the general population, found meaning in different areas of life, feeling greater satisfaction in those areas. Interesting to the extend that the meaning is related positively with good physical health and negatively with chronic disease [36]. As well as the presence of a disease leads to less meaning in life, taking into account all the difficulties, sequels, and losses that the disease process causes in the life and functioning of the subject (e.g., [37,33,38]).

However, some cancer survivors reveal having more PIL after having experienced the disease than before being diagnosed [39]. A diagnosis like cancer can boost the search for meaning and precipitate changes in people's lives in terms of values and lifestyles, which increase spirituality and appreciation for life, new opportunities, improve affective relationships, and make them more aware of how they should live life [40].

Despite the contributions, limitations should be pointed out, such as the fact that this was a transversal study, conducted in one moment of evaluation, not allowing for cause-effect relationships between the variables to be drawn. Future studies should examine the relationship between variables at various evaluation moments over time so as to control groups by stages of the disease process and specify the types of cancer.

In conclusion, the achieved results allow us to expand understanding about the relationship between EI, PIL, and SWL. Especially the area of EI in cancer disease, and the relationship between EI and PIL, that have a significant reduced research. On the other hand, the need to investigate and prioritize the EI construct in health and disease area is revealed. Moreover, the results may be useful for psychological practice, indicating new and positive directions on the presence of key components in the intervention area, optimizing the development and acquisition of emotional skills, and the creation of life goals. Effectiveness in achieving these goals will result in increased satisfaction in the lives of participants, particularly before a disease process. The results show the need to develop specific scale of EI and PIL in cancer context, in the case of these variables promoting SWL in patients. Lastly, the results demonstrated the convergence between the constructs of EI, PIL, and SWL, highlighting the principles of positive psychology, which aim to discover the variables to have a good life. 


\section{References}

1. Strine TW, Chapman DP, Balluz LS, Moriarty DG, Mokdad AH. The associations between life satisfaction and health-related quality of life, chronic illness, and health behaviours among US community-dwelling adults. J Community Health 2008;33:40-50. DOI:10.1007/s10900-007-9066-4.

2. Hewitt M, Greenfield S, Stovall E. From Cancer Patient to Cancer Survivor: Lost in Transition, National Academies Press: Washington, DC, 2006.

3. Seligman MEP, Steen TA, Park N, Peterson C. Positive psychology progress: empirical validation of interventions. Am Psychol 2005;60(5):410-421. DOI:10.1037/0003-066X.60.5.410.

4. Ruini C, Vescolli F. The role of gratitude in breast cancer: its relationships with posttraumatic growth, psychological well-being and distress. J Happiness Stud 2013;14(1):263-274. DOI:10.1007/s10902-012-9330-x.

5. Martins A, Ramalho N, Morin E. A comprehensive meta-analysis of the relationship between emotional intelligence and health. Pers Individ Dif 2010;49:554-564. DOI:10.1016/j.paid.2010.05.029.

6. Zeidner M, Matthews G, Roberts RD. The emotional intelligence, health, and wellbeing nexus: what have we learned and what have we missed? Appl Psychol Health and Well-Being 2012;4(1):1-30. DOI:10.1111/ j.1758-0854.2011.01062.x.

7. Rey L, Extremera-Pacheco N, Trillo L. Exploring the relationship between emotional intelligence and health-related quality of life in patients with cancer. J Psychosoc Oncol 2013;31(1):51-64.

8. Thompson BL, Waltz J, Croyle K, Pepper AC. Trait meta-mood and affect as predictors of somatic symptoms and life satisfaction. Pers Individ Dif 2007:43(7):1786-1795. DOI:10.1016/j.paid.2007.05.017.

9. Donohoe J, Greene D. Social relationships mediate the relation between emotional intelligence and meaning in life. Psi Chi J Undergrad Res 2009;14(2):59-64.

10. Zysberg L. Loneliness and emotional intelligence. J Psychol-Interdiscip Appl 2012;146(1-2):37-46. DOI:10.1080/00223980.2011.574746.

11. Steger MF, Frazier P, Oishi S, Kaler M. The meaning life questionnaire: assessing the presence of and search for meaning in life. J Couns Psychol 2006;53(1):80-93. DOI:10.1037/00220167.53.1.80.

12. Bronk KC, Hill PL, Lapsley DK, Talib TL, Finch H. Purpose, hope, and life satisfaction in three age groups. J Posit Psychol 2009;4(6):500-510. DOI:10.1080/17439760903271439.

13. Park N, Park M, Peterson C. When is the search for meaning related to life satisfaction? Appl Psychol Health and Well-Being 2010;2(1):1-13. DOI:10.1111/j.1758-0854. 2009.01024.x.
14. Kallay E, Miclea M. The role of meaning in life in adaptation to life threatening illness. Cogn Brain Behav 2007;11:159-170.

15. Pereira-Teques A, Llorca-Ramón G, BuenoCarrera G, Pais-Ribeiro J, Teques P. Desenvolvimento e avaliação das características psicométricas do Questionário de AutoPercepção de Inteligência Emocional (QIEAP). Revista Psicologia: Reflexão e Crítica 2015;28(2):213-222. DOI:10.1590/1678-7153. 201528210.

16. Peralta E, Silva M. Teste dos objectivos de vida (PIL_R). In Avaliação psicológica: Instrumentos validados para a população portuguesa, Gonçalves M, Simões M, Almeida L, Machado C (eds). Quarteto: Coimbra, 2003; 61-73.

17. Schulenberg SE, Schnetzer LW, Buchanan EM. The purpose in life test-short form: development and psychometric support. J Happiness Stud 2011;12(5):861-876. DOI:10.1007/ s10902-010-9231-9.

18. Neto F. Satisfaction with life among Portuguese adolescents. J Youth Adolesc 1993;22(2):125-134. DOI:10.1007/BF01536648.

19. Pavot W, Diener E. The satisfaction with life scale and the emerging construct of life satisfaction. J Posit Psychol 2008;3(2):137-152. DOI:10.1080/17439760701756946.

20. Raykov T. Estimation of composite reliability for congeneric measures. Appl Psychol Meas 1997:2:173-184. DOI:10.1177/01466216970212006.

21. Graham JM. Congeneric and (essentially) tau-equivalent estimates of score reliability: what they are and how to use them. Educ Psychol Meas 2006;66:930-944. DOI:10.1177/ 0013164406288165.

22. Fornell C, Larcker DF. Evaluating structural equation models with unobservable variables and measurement error. J Mark Res 1981;18 (1):39-50. DOI:10.2307/3151312.

23. Hair J, Black B, Babin B, Anderson R. Multivariate Data Analysis, Prentice Hall: Saddle River, NJ, 2010.

24. Byrne B. Structural Equation Modelling with AMOS: Basic Concepts, Applications, and Programming (2nd ed.), Lawrence Erlbaum Associates: Mahwah, NJ, 2010.

25. Kline R. Beyond Significance Testing: Reforming Data Analysis Methods in Behavioral Research (3rd ed.), American Psychological Association: Washington, DC, 2011.

26. Nevitt J, Hancock GR. Performance of bootstrapping approaches to model test statistics and parameter standard error estimation in structural equation modeling. Struct Equ Modeling 2001;8(3):353-377. DOI:10.1207/ S15328007SEM0803_2.

27. Faul F, Erdfelder E, Lang AG, Buchner A. $G^{*}$ Power: a flexible statistical power analysis program for the social, behavioral, and biomedical sciences. Behav Res Methods 2007;39(2):175-191. DOI:10.3758/BF03193146.

28. Gohm CL, Clore G. Tour latent traits off emotional experiences and their involvement in attributional style, coping and well-being. Cogn Emot 2002;16(4):495-518.

29. Extremera-Pacheco N, Fernández-Berrocal P. Una guía práctica de los instrumentos actuales de evaluación de la inteligencia emocional. In Manual de inteligencia emocional, Navas J, Berrocal P (eds). Ediciones Pirámide: Madrid, 2007; 99-122.

30. Costa S, Petrides KV, Tillmann T. Trait emotional intelligence and inflammatory diseases. Psychol Health Med 2014;19:180-189. DOI:10.1080/13548506.2013.802356.

31. Ciarrochi JV, Deane FP, Anderson S. Emotional intelligence moderates the relationship between stress and mental health. Pers Individ Dif 2002;32:197-209. DOI:10.1016/S01918869(01)00012-5

32. Augusto-Landa JM, Pulido-Martos M, LópezZafra E. Does perceived emotional intelligence and optimism/pessimism predict psychological wellbeing? J Happiness Stud 2011;12(13):463-474. DOI:10.1007/s10902-010-9209-7.

33. Jim HS, Andersen BL. Meaning in life mediates the relationship between social and physical functioning and distress in cancer survivors. Br J Health Psychol 2007;12(3):363-381. DOI:10.1348/135910706X128278.

34. Schlegel RJ, Manning MA, Bettencourt BA. Expectancy violations and the search for meaning among breast cancer survivors. $J$ Posit Psychol 2013;8(5):387-394. DOI:10.1080/ 17439760.2013.807354.

35. Fegg MJ, Brandstätter M, Kramer M, Kögler M, Haarmann-Doetkotte S, Borasio GD. Meaning in life in palliative care patients. $J$ Pain Symptom Manage 2010;40(4):502-509. DOI:10.1016/j.jpainsymman.2010.02.010.

36. Skrabski A, Kopp M, Rozsa S, Rethelyi J, Rahe RH. Life meaning: an important correlate of health in the Hungarian population. Int $J$ Behav Med 2005;12:78-85. DOI:10.1207/ s15327558ijbm1202_5.

37. Fleer J, Hoekstra HJ, Sleijfer DT, Tuinman MA, Klip EC, Hoekstra-Weebers JE. Quality of life of testicular cancer survivors and the relationship with sociodemographics, cancerrelated variables, and life events. Support Care Cancer 2006;14:251-259. DOI:10.1007/ s00520-005-0879-3.

38. Simonelli LE, Fowler J, Maxwell GL, Andersen BL. Physical sequelae and depressive symptoms in gynecologic cancer survivors: meaning in life as a mediator. Ann Behav Med 2008;35:275-284. DOI:10.1007/s12160-008-9029-8.

39. Speck P. Spiritual religious issues in care of the dying. In Care of Dying: A Pathway to Excellence (2nd edn), Ellershaw J, Wilkinson $S$ (eds). Oxford University Press Inc: New York, 2011; 106-126.

40. Boyraz G, Horne SG, Sayger TV. Finding positive meaning after loss: the mediating role of reflection for bereaved individuals. $J$ Loss Trauma 2010;15(3):242-258. DOI:10.1080/ 15325020903381683 
Copyright of Psycho-Oncology is the property of John Wiley \& Sons, Inc. and its content may not be copied or emailed to multiple sites or posted to a listserv without the copyright holder's express written permission. However, users may print, download, or email articles for individual use. 